\title{
SIGNAL PROCESSING IN HIGH SPEED OTDM NETWORKS
}

\author{
P. R. Prucnal, P. Toliver, I. Glesk, R. Runser, and K.-Li Deng \\ Department of Electrical Engineering, Princeton University, Princeton, NJ 08544, USA \\ prucnal@ee.princeton.edu \\ ptoliver@phoenix.princeton.edu \\ glesk@ee.princeton.edu \\ kungdeng@phoenix.princeton.edu
}

With the amount of Internet traffic doubling every 100 days [1], it is clear that the use of lightwave technologies will be absolutely necessary to meet the bandwidth requirements of future local and wide-area communication systems. Electronic packet-switching is an efficient technique for achieving maximum utilization of a given channel, as proven by the current Internet. In addition, given sufficient channel bandwidth, packet switching can provide adequate low latency communication for the majority of applications. The evolution of packet-switching to the optical domain is a natural extension, provided that the capabilities as well as the limitations of lightwave technologies are taken into consideration during the design process. The inherent low loss properties, small size, low cost, and multi-terahertz bandwidth of optical fiber make it a nearly ideal transmission channel. However, when compared with electronics, the number of photonic devices currently available to implement a practical system is limited. Therefore, it is necessary to minimize the complexity of the system and take advantage of the limited available technologies.

A major issue in designing high-speed optical networks is how to utilize the bandwidth of the fiber efficiently. Currently, there are two primary techniques for multiplexing data onto a single fiber: time-division multiplexing (TDM), and wavelength-division multiplexing (WDM). A great deal of recent research in optical networks has been focused in the area of WDM technology [2] and some groups are currently working on WDM packet switching [3-6]. Although TDM technologies have not advanced as quickly as WDM due to the difficulties in developing ultrafast demultiplexing and processing devices as well as the lack of optical TDM technology transition to the commercial market, the use of ultrafast TDM can simplify some areas of a system implementation since only a single wavelength is used in the network. For example, systems performance issues such as four wave mixing (FWM) and component spectral nonuniformities will impose limitations on the capabilities of a WDM system. Although ultrafast TDM systems are not limited by these effects, they have their own set of technical challenges such as network synchronization and nonlinearities in the system due to the high peak power of ultrashort pulses. A table summarizing the major performance limitations found in both systems is given in Table 1.

Table 1.

Comparison of system performance limitations in TDM and WDM optical networks

\begin{tabular}{|c|c|}
\hline \multicolumn{2}{|c|}{ System performance limitations } \\
\hline TDM Systems & WDM Systems \\
\hline $\begin{array}{c}\text { Power budget- } \\
\text { short pulse amplification }\end{array}$ & $\begin{array}{c}\text { Power budget- } \\
\text { wide bandwidth amplification }\end{array}$ \\
\hline ASE noise accum. & ASE noise accum. \\
\hline $\begin{array}{c}\text { Dispersion- } \\
\text { pulse broadening }\end{array}$ & $\begin{array}{c}\text { Dispersion- } \\
\text { adj. channel walkoff }\end{array}$ \\
\hline Nonlinearities- & $\begin{array}{c}\text { Nonlinearities- } \\
\text { XPM, FWM }\end{array}$ \\
\hline SPM & $\begin{array}{c}\text { Adjacent wavelength } \\
\text { channel crosstalk }\end{array}$ \\
\hline Adjacent time \\
channel crosstalk & $\begin{array}{c}\text { Component spectral } \\
\text { nonuniformities }\end{array}$ \\
\hline Synchronization \& jitter &
\end{tabular}

A number of large groups are currently doing research on ultrafast TDM technology including BT Labs [7, 8], NTT [9], Heinrich-Hertz-Institut [10], MIT Lincoln Laboratory [11], University of Michigan [12] as well as many others. Some applications that can benefit from TDM technologies include localized networks such as those found in processor interconnects and computer LANs as well as larger area networks such as the Next Generation Internet (NGI). 
OTDM networks based on our recently-developed Terahertz Optical Asymmetric Demultiplexer (TOAD) will enable construction of crossbar interconnect systems with aggregate capacities approaching $1 \mathrm{~Tb} / \mathrm{s}$. The synchronicity inherent in an OTDM system can be exploited to implement efficient arbitration and control methods that scale linearly with the number of attached nodes. OTDM based interconnect systems challenge the current generation of switching fabrics that use electronic routers by offering low latencies, high bandwidth, and globally visible event ordering. Furthermore, nodes are connected to a central switching hub in a star-like fashion where each node requires two optical fiber connections, independent of the system size.

This paper presents the design and experimental results of an optical packet-switching testbed capable of performing message routing with single wavelength TDM packet bit rates as high as $100 \mathrm{~Gb} / \mathrm{s}$. The physical topology of the Packetswitched Optical Networking Demonstration (POND) node is based on an 8-node ShuffleNet architecture. The key enabling technologies required to implement the node such as ultrafast packet generation, high-speed packet demultiplexing, and efficient packet routing schemes are described in detail. Therouting approach taken is a hybrid implementation in which the packet data is maintained purely in the optical domain from source to destination whereas control information is read from the packet header at each node and converted to the electrical domain for an efficient means of implementing routing control. The technologies developed for the interconnection network presented in this paper can be applied to larger metropolitan and wide area networks as well. In this talk recent experimental demonstrations of both ultrafast demultiplexing and high-speed time slot tuning that show that a 100 node network with an aggregate capacity of $100 \mathrm{~Gb} / \mathrm{s}$ is practically achievable. Additionally, will be presented the technologies that enable this broadcast star network fabric also can be applied to high speed all-optical packet-switching networks. Our recent $100 \mathrm{~Gb} / \mathrm{s}$ packet-switched multihop testbed using ultrafast demultiplexing and efficient packet compression demonstrate the feasibility of this approach to provide a reliable means of improving the capacity of all-optical networks.

References:

[1] L. Margherio et al., The Emerging Digital Economy, U.S. Department of Commerce (1998)

[2] M. Fujiwara, M. S. Goodman, M. J. O’Mahony, O. K. Tonguz, and A. E. Willner, "Special issue on multiwavelength optical technology and networks," J. Lightwave Technol., vol. 14, June 1996

[3] S. P. Monacos, J. M. Morookian, L. Davis, L. A. Bergman, S. Forouhar, and J. R. Saur, "All-optical WDM packet networks," J. Lightwave Technol., vol. 14, pp. 1356-1370, June 1996

[4] M. Shell, M. D. Vaughn, A. Wang, D. J. Blumenthal, P. J. Rigole, and S. Nilsson, "Experimental demonstration of an alloptical routing node for multihop wavelength routed networks," IEEE Photon. Technol. Lett., vol. 8, pp. 1391-1393, Oct. 1996

[5] R. Monnard, M. Zirngibl, C. R. Doerr, C. H. Joyner, and L. W. Stulz, "Demonstration of an eight-wavelength fast packet switching transmitter of 2.5-Gb/s bit stream," IEEE Photon. Technol. Lett., vol. 10, pp. 430-432, March 1998

[6] K. Bala, F. Chung, and C. A. Brackett, "Optical wavelength routing, translation, and packet/cell switched networks," $J$. Lightwave Technol., vol. 14, pp. 336-343, March 1996

[7] D. M. Spirit, A. D. Ellis, and P. E. Barnsley, "Optical time division multiplexing: systems and networks," IEEE Commun. Mag., vol. 32, pp. 56-62, Dec. 1994

[8] A. D. Ellis, D. M. Patrick, D. Flannery, R. J. Manning, D. A. O. Davies, and D. M. Spirit, "Ultra-high-speed OTDM networks using semiconductor amplifier-based processing nodes," J. Lightwave Technol., vol. 13, pp. 761-770, May 1995

[9] M. Saruwatari "High-speed optical signal processing for communications systems," IEICE Trans. Commun., vol. E78-B, pp. 635-643, May 1995

[10] H. G. Weber, R. Ludwig, W. Pieper, E. Jahn, N. Agrawal, R. Schnabel, M. Eiselt, H. J. Ehrke, and A. Ehrhardt, “Optical time-domain-demultiplexing techniques using semiconductor laser amplifiers," Proc. $22^{\text {nd }}$ Europ. Conf. On Opt. Comm. (ECOC '96), vol. 4, pp 4.3-4.6, Sept. 1996

[11] R. A. Barry, V. W. S. Chan, K. L. Hall, E. S. Kintzer, J. D. Moores, K. A. Rauschenbach, E. A. Swanson, L. E. Adams, C. R. Doerr, S. G. Finn, H. A. Haus, E. P. Ippen, W. S. Wong, and M. Haner, "All-optical network consortiumultrafast TDM networks," IEEE J. Select. Areas Commun., vol. 14, pp. 999-1011, June 1996

[12] T. J. Xia, Y. Liang, K. H. Ahn, J. W. Lou, O. Boyraz, Y. H. Kao, X. D. Cao, S. Chaikamnerd, J. K. Anderson, and M. N. Islam., "All-optical packet-drop demonstration using 100-Gb/s words by integrating fiber-based components," IEEE Photon. Technol. Lett., vol. 10, pp. 153-155, Jan. 1998 